\title{
Acute Schistosomiasis Outbreak in the Metropolitan Area of Belo Horizonte, Minas Gerais: Alert about the Risk of Unnoticed Transmission Increased by Growing Rural Tourism
}

\author{
Martin J Enk, Amanda Amorim, Virginia T Schall ${ }^{+}$ \\ Laboratorio de Educação em Saúde, Centro de Pesquisas René Rachou-Fiocruz, Av. Augusto de Lima 1715, 30140-002 \\ Belo Horizonte, MG, Brasil
}

\begin{abstract}
The present article describes the occurrence of 17 cases of acute schistosomiasis in the metropolitan area of Belo Horizonte, state of Minas Gerais, Brazil. All individuals affected took a bath in a swimming pool of a holiday resort that was provided with water from a nearby brook. The apparently clean water and the absence of snails in the pool gave the wrong impression that there was no risk for infection. During a malacological survey at the site snails of the species Biomphalaria glabrata were found and tested positive for Schistosoma mansoni. All the patients live in the middle-class area of Barreiro, metropolitan area of Belo Horizonte and have medium grade school education. The difficulties in establishing the right diagnosis is expressed by the search for medical attention in 17 different medical facilities, the wide range of laboratory test and the inadequate treatment administration. A lack of knowledge about the disease was found in all groups studied. The booming rural tourism in endemic areas is identified as a probable risk factor for infection, especially for individuals of the non-immune middle and upper class parts of the society in urban centers. Special attention is given to a multidisciplinary approach to the complex issue of disease control and prevention.
\end{abstract}

Key words: Schistosoma mansoni - acute schistosomiasis - health education - rural tourism - control - Belo Horizonte Minas Gerais - Brazil

Schistosomiasis mansoni in Brazil was considered a mainly rural endemic disease with a more chronic course, affecting the low-income population. In the state of Minas Gerais, schistosomiasis mansoni is prevalent in 519 out of 853 municipalities, with an estimated number of 1,000,000 infected people in an area of $300000 \mathrm{~km}^{2}$ (Katz 1998). More recent estimates, based on data from Fundação Nacional de Saúde and Instituto Brasileiro de Geografia e Estatística, were described as probably not reflecting the true situation since the population sample used was not originally selected for this purpose (Katz \& Peixoto 2000). Furthermore the exclusion of metropolitan areas may lead to an underestimation of the real figure.

During the last decades the traditional epidemiological pattern showed a tendency to change. Accelerating migration from the countryside to cities threatened to overwhelm existing water and sanitation systems, and to increase urban schistosomiasis (Suassuna \& Coura 1969, Sturrock 2001). In Brazil outbreaks of acute schistosomiasis, especially in urban areas, were observed and documented with a certain frequency (Ferreira et al. 1960, 1966, Coura et al. 1970, Neves 1992, Rabello 1995, Barbosa et al. 2001). The increase of acute schistosomiasis cases also indicates that a non-immune fraction of the population (people from metropolitan, non-endemic areas with no acquired immunity) became exposed to the disease.

Financial support: CNPq, Fapemig

${ }^{+}$Corresponding author. Fax: +55-31-3295.3115. E-mail: vtschall@cpqrr.fiocruz.br

Received 11 March 2003

Accepted 18 June 2003
The acute toxemic phase of schistosomiasis is more common in non-immune individuals and characterized by a wide diversity of symptoms, which may vary from case to case (Manson-Bahr \& Bell 1989). The most common manifestations are fever, general weakness, headache, nausea, vomiting, diarrhea, unproductive cough, hepatomegaly, splenomegaly and skin reactions accompanied by a marked eosinophilia (Neves 1992, Rabello 1995).

In the present article the occurrence of 17 cases of acute schistosomiasis in the metropolitan area of Belo Horizonte is discussed. Special attention is given to a multidisciplinary approach to the complex issue of disease control and prevention.

\section{MATERIALS AND METHODS}

Patients - Initially a group of 24 individuals was included in the present study. Six of them denied cooperation and had to be excluded. All of them (18 volunteers) spent the weekend from 21 to 22 of April 2002 at a private holiday resort. They took a bath in the swimming pool of this locality that was provided with water from a nearby brook. The group consisted of nine females and nine males (mean age of 21.5 years, standard deviation $\mathrm{s}=5.7$ ).

All of them live in the middle-class area of Barreiro, metropolitan area of Belo Horizonte and have medium grade school education.

Additionally, a group of seven individuals was included. They were permanent residents of the resort. Stool samples of them were taken and examined for eggs of Schistosoma mansoni using the Kato Katz method (Katz et al. 1972).

Transmission site - The site of infection is Ibirité, metropolitan area of Belo Horizonte, Minas Gerais. The 
valley is characterized by various little brooks, marshy areas and springs. The private holiday resort can be rented on a daily basis and is used for leisure purposes especially during weekends (Fig. 1). A little brook forms the boundary on two sides of the location and it serves as water source for the pool behind the house. Water from the brook is collected in an open water tank before it is brought through a tube to the swimming pool (Fig. 2). The tank is placed at a distance of approximately $70 \mathrm{~m}$ away from the pool.

Diagnosis and medical evaluation - The patients searched medical attention in various medical facilities nearby their living area. This variety of medical facilities resulted in a considerable difference of laboratory examinations, which reflects the different approach of making the diagnosis. Nevertheless medical evaluation was done in all patients who presented symptoms. The evaluation included medical history, complete clinical

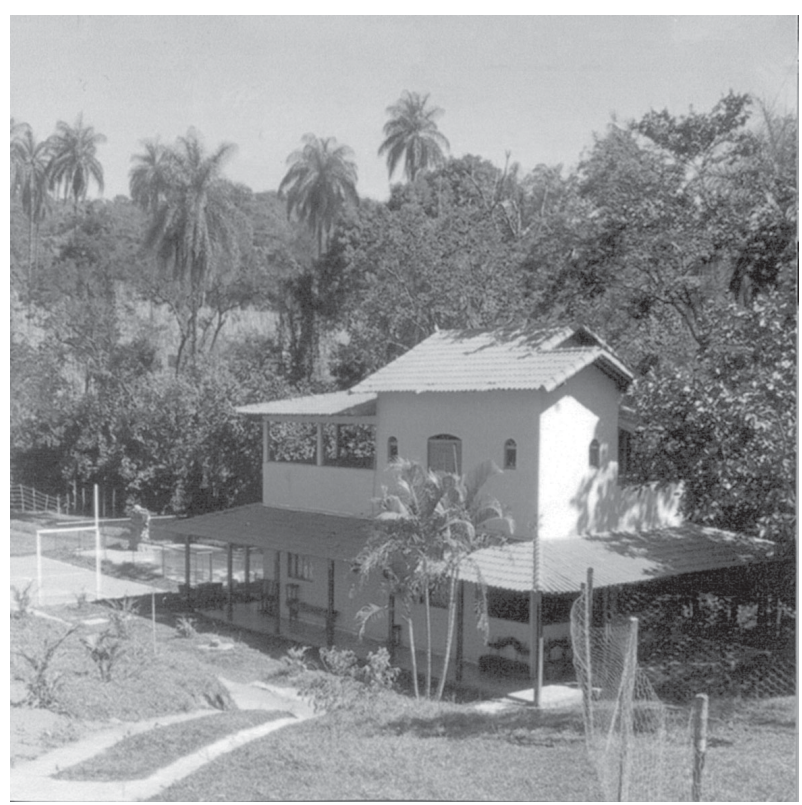

Fig. 1: the private holiday resort with the swimming pool, where infection took place.

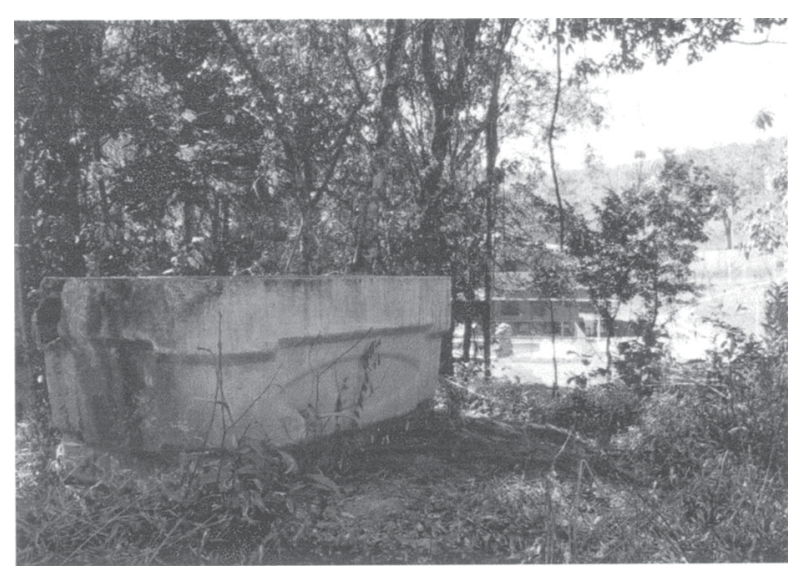

Fig. 2: the tank, which provided the water for the swimming pool of the resort. It was inhabited by snails and is therefore considered as source of infection. examination, blood count and stool sample of some patients. Further clinical investigations such as chest $\mathrm{X}$-rays, CT scans, serological tests, liver enzymes test, and urinalysis were carried out according to symptoms and severity of the disease. The diagnosis of acute schistosomiasis was established through common epidemiological background and presented symptoms in combination with positive stool samples, positive serological test (immune fluorescent test) or alterations in the white blood count (eosinophilia).

Malacological survey - A team of the Centro de Pesquisas René Rachou visited the site on June 18th and July 25 th, 2002. The purpose of these visits was to identify and explore possible sources of infection and to collect snails. During the first field trip snails were collected in a little pond, $300 \mathrm{~m}$ distant from the site of infection. The water of the pond drained into the brook, which passes nearby the resort. Snail collection was performed with perforated metal dippers fixed on a wooden stick (Thiengo 1995). Wooden tweezers were also used for the collection procedure. During the second trip mollusks were collected with wooden tweezers $(20 \mathrm{~cm}$ and $30 \mathrm{~cm}$ length) from the water tank which provided the water for the swimming pool. All snails collected were sent to the laboratory to be identified, measured and tested three times for infection with $S$. mansoni under artificial light.

Exploratory knowledge investigation - The 17 members of the study group, who felt sick, participated in an exploratory investigation about their knowledge of schistosomiasis. Special attention was given in order to obtain information about their knowledge of the disease before the infection took place. The interview was guided by a semi-structured questionnaire including topics such as transmission of the disease, recognition of the intermediate host and its habitat and general knowledge about waterborne diseases. Possible prior contacts with schistosomiasis as well as an increase of general knowledge of the disease before and after illnesses were evaluated. The interviewer was instructed to talk freely about the issues and to make notes of the information given during the survey. The answers of the patients were classified by keywords in order to apply the same standards for each interview and facilitate the evaluation. The following keywords were used: water, faeces, contamination (of water with infective faeces), snails, and cercaria. The maximum of five points means complete knowledge and the minimum of zero points indicates no knowledge at all.

\section{RESULTS}

Patients - All individuals took a bath in the swimming pool of the resort. The water was apparently clean and no snails were seen in the water. Shortly after the bath some of them noticed itchy papules and surrounding edema, which corresponds to the cercarial dermatitis or swimmer's itch during the stage of invasion. Later on, 17 individuals felt sick with acute schistosomiasis. The symptoms appeared the earliest 11 days and the latest 62 days after contact. The mean incubation period amounted to 32 days (standard deviation $\mathrm{s}=14.6$ ). Outpatient treatment was given to 13 of them and four were hospitalized due to the 
severity of the disease. The symptoms presented by the patients are described in Table I. Only one individual continued without complaints.

The number and severity of symptoms presented by each patient varied significantly, according to the organ system involved and the immune response of the patient. Nine individuals $(50 \%)$ presented more than nine symptoms out of 11 .

Diagnosis and medical evaluation - As the study was done retrospectively, the laboratory tests varied from patient to patient reflecting the number of different medical facilities involved and their approach to find the diagnosis. It is worth noting that patients searched for medical attention in 17 different medical facilities. The number of medical facilities visited per patient varied from one to four (one medical facility by four patients, two medical facilities by eight patients, three medical facilities by three patients, and four medical facilities by one patient). Table II shows the laboratory tests done in each patient that

TABLE I

Clinical manifestations of the 17 patients with symptoms of acute schistosomiasis

\begin{tabular}{lcr}
\hline Symptoms & Patients & $\%$ \\
\hline Fever & 17 & 100 \\
Asthenia & 15 & 88 \\
Diarrhoea & 14 & 82 \\
Dry cough & 14 & 82 \\
Headache & 13 & 76 \\
Weight loss & 13 & 76 \\
Abdominal colic & 11 & 64 \\
Nausea/vomiting & 11 & 64 \\
Body pain & 9 & 53 \\
Rash & 8 & 47 \\
Facial oedema & 7 & 41 \\
\hline
\end{tabular}

established the diagnosis together with the common epidemiological history.

All patients were treated either with Praziquantel (50 $\mathrm{mg} / \mathrm{kg}$, single dose, patient 15 ) or with Oxamniquine (20 $\mathrm{mg} / \mathrm{kg}$, two doses, all other patients). Supportive therapy and steroids were provided according to the severity of symptoms.

The stool samples of the permanent residents of the holiday resort showed the following results. From the seven people examined, five (71\%) proved positive for schistosomiasis, and the number of eggs per gram varied from 12 to 132. No one presented symptoms of the disease.

Malacological survey - A total number of 101 molluscs (92 from the pond and nine from the water tank) were collected. One was classified as Physa sp. and 100 were identified as $B$. glabrata with sizes varying between 9 and $25 \mathrm{~mm}$. From the $91 \mathrm{~B}$. glabrata of the pond 57 were alive. Out of these, a number of seven snails (13.8\%) were positive for $S$. mansoni cercariae. From the nine $B$. glabrata, out of the water tank, eight were alive, and one snail $(16.6 \%)$ was positive. In seven molluscs, cercariae macrogranulosa were found. The water tank was identified as the source of infection.

Exploratory knowledge investigation - The investigation revealed that three patients $(17.7 \%)$ have never heard about schistosomiasis before. The other 14 $(82.3 \%)$ stated to have learned about the disease by different means: school $(11$ individuals $=78.5 \%)$; television (one individual $=7.1 \%$ ); friends (one individual $=7.1 \%$ ); a relative who felt sick one and a half years ago (one individual $=7.1 \%$ ). A group of nine individuals (64.2\%) could not remember when they had learned about the disease. The remaining four $(28.5 \%)$ indicated a period longer than five years since having heard about schistosomiasis.

The results of the knowledge evaluation about transmission of the disease are illustrated in Table III,

TABLE II

Conclusive laboratory tests for schistosomiasis per patient in an investigation of 17 individuals suffering from acute schistosomiasis

\begin{tabular}{rcccc}
\hline Patient & Stool sample & Immunofluorescence & Total leucocyte count & Eosinophils (\%) \\
\hline 1 & Neg & $1: 80$ & - & - \\
2 & Pos & - & 12,000 & 15 \\
3 & Pos & $1: 160$ & - & - \\
4 & - & $1: 80$ & - & - \\
5 & Pos & $1: 320$ & 14,400 & 30 \\
6 & Pos & - & 9,000 & 21 \\
7 & Pos & - & 14,900 & 30 \\
8 & Pos & Neg & - \\
9 & Pos & - & - & - \\
10 & Pos & - & 6,900 & 4 \\
11 & Neg & $1: 80$ & 38,400 & 52 \\
12 & - & - & 14,400 & 21 \\
13 & Pos & - & 11,900 & - \\
14 & Neg & - & - & 2 \\
15 & Pos & - & 7,900 & 2 \\
16 & Pos & - & 8,500 & 68 \\
17 & Neg & $1: 320$ & 16,800 & \\
\hline
\end{tabular}

-: not carried out; pos: positive; neg: negative 
using the keywords.

A group of seven individuals (41.2\%) did not have any knowledge at all. Minimum knowledge (total score 1 and 2) was shown by seven individuals and medium knowledge (total score 3 and 4) by two. Only one individual achieved a total score of 5 . The most frequently quoted keyword was water, followed by snail and feces (Table III).

The question about recognizing the mollusc ( $B$. glabrata) was answered positively by four individuals. All of them had seen the snail on pictures, but never in its natural habitat.

Asked about other water borne diseases, five individuals could not give any further information. The other twelve individuals indicated different diseases as follows: cholera (a) and other helminthic disease (b) was quoted by only one individual each. Cholera, dengue fever and leptospirosis (a), dengue fever alone (b) and mycosis (c) were cited by two persons each. Cholera and dengue fever was the answer of four individuals.

Finally the group was asked what they had learned about the disease since they had fallen sick. An overview of the statements is given in Table IV.

Following Table IV, the statement "not to swim in unknown water" - was quoted seven times, followed by "the disease can kill without treatment" six times, "transmission through water" four times, "transmission through snails" and "symptoms" three times. Knowledge about the cycle of infection was mentioned only twice.

\section{DISCUSSION}

This study shows that schistosomiasis mansoni was transmitted in a rural area from non-symptomatic positive residents through infected intermediate hosts to visitors from an urban area who never had contact with the disease before and who developed acute schistosomiasis after

TABLE III

Results of the exploratory knowledge investigation about the transmission of Schistosoma mansoni in a group of 17 patients according to keywords (vertical columns) and for each single patient (horizontal rows)

\begin{tabular}{|c|c|c|c|c|c|c|}
\hline Patient & Water & Snail & Feces & Cercaria & Contamination & Total \\
\hline 1 & + & + & + & + & + & 5 \\
\hline 2 & + & - & + & + & - & 3 \\
\hline 3 & - & - & - & - & - & 0 \\
\hline 4 & - & - & - & - & - & 0 \\
\hline 5 & - & + & - & - & - & 1 \\
\hline 6 & + & + & + & - & - & 3 \\
\hline 7 & + & - & - & + & - & 2 \\
\hline 8 & - & - & - & - & - & 0 \\
\hline 9 & - & - & - & - & - & 0 \\
\hline 10 & + & - & - & - & - & 1 \\
\hline 11 & - & + & - & - & - & 1 \\
\hline 12 & - & - & + & - & - & 1 \\
\hline 13 & - & + & - & - & - & 1 \\
\hline 14 & + & - & - & - & - & 1 \\
\hline 15 & - & - & - & - & - & 0 \\
\hline 16 & - & - & - & - & - & 0 \\
\hline 17 & - & - & - & - & - & 0 \\
\hline Total (\%) & $\begin{array}{c}6 \\
(35.3 \%)\end{array}$ & $\begin{array}{c}5 \\
(29.4 \%)\end{array}$ & $\begin{array}{c}4 \\
(23.5 \%)\end{array}$ & $\begin{array}{c}3 \\
(17.7 \%)\end{array}$ & $\begin{array}{c}1 \\
(5.9 \%)\end{array}$ & \\
\hline
\end{tabular}

+: keyword mentioned in the exploratory knowledge investigation; -: keyword not mentioned in the exploratory knowledge investigation

TABLE IV

Results of statements of additional knowledge about schistosomiasis mansoni given by 17 individuals with acute schistosomiais

\begin{tabular}{ll}
\hline Patient & Statement \\
\hline 1,9 & Symptoms \\
$2,13,16$ & Can kill without treatment \\
3,4 & Transmission through water \\
5 & Transmission through water, cycle of infection \\
$6,7,12$ & Can kill without treatment, not to swim in unknown water \\
8 & Transmission through water, cycle of infection, not to swim in unknown water \\
10 & Transmission through snails \\
11 & Not to swim in unknown water \\
15 & Symptoms, transmission through snails \\
17 & Transmission through snails, not to swim in unknown water \\
\hline
\end{tabular}


infection. The proliferation of rural tourism in metropolitan areas which is steadily increasing since the early nineties may be an important contributing factor to this way of transmission. The "hotel-fazendas" (farm hotels) and "pousadas" (boarding houses), often located in endemic areas, offer a wide range of adventure and ecological activities. Special attention of the owners is given to preserve a natural environment on the site in order to please the guest from urban centers. Unintentionally, in this way, the ideal habitat for the intermediate host of this disease is also created. Unfortunately, the neighborhood of these locations accommodates rural communities without any type of sanitation and thus represents a permanent risk of contamination of the flowing water, which is highly praised by the tourism business. This situation contributes to the propagation of schistosomiasis. From the public health point of view, one may argue that the current system of disease control and prevention is insufficient to avoid such occurrences. Current strategies, mainly based on chemotherapy and molluscicide application, produced a significant decrease in prevalence and mortality during the past 20 years (Katz 1998). However, a lot of positive non-symptomatic carriers escaped. They maintain the disease on lower prevalence levels and trigger spreading of the disease into uninfected areas (Carmo \& Baretto 1994, Amorim 1997, Coura-Filho 1997a, Barbosa 1998, Grault et al. 1998). In our case, this group is represented through the infected, nonsymptomatic residents of the site who were not detected through the common health system. Molluscicide application is inappropriate because the area is used for agriculture and stockbreeding. Considering what has been said, the current strategy (treatment and molluscicide application) is a very useful tool to decrease prevalence and mortality on a nation wide level but is not enough to control and prevent the disease on a local level. Consequently, other measures have to be adopted to achieve this goal. Sanitation, water supply and sewage draining may be the choice on a nation wide level. However, health education offers the flexibility necessary to meet local needs. As local human resources are trained, they contribute with their local experience and knowledge by adapting the necessary measurements adequately for sustainable improvement. In the example of our study a lesson was given to the owner of the resort about schistosomiasis in general and the way of its transmission in particular. The information provided in combination with some technical recommendations resulted in a tremendous improvement of the site. Now the swimming pool receives water from a well, approximately $600 \mathrm{~m}$ away. The water is brought through a closed tube system to a closed water tank made of concrete. The water is pumped from there through tubes into the swimming pool. This system ensures that there isn't any contact of the water with the environment before entering the pool. Shields warning about contamination were put along the brook which surrounds the site. The little pond $300 \mathrm{~m}$ distant of the site was drained and filled with earth. The area will be used for crop plantation.

In our study, the incubation period matches the range of a 2 to 8 weeks period, which is accepted as standard in the literature (Neves 1992, Rabello 1995). Also the symptoms presented by the patients and their distribution are in accordance with findings of other authors (Ferreira et al. 1966, Coura et al. 1970, Rabello 1995, Barbosa et al. 2001).

The difficulties in establishing the diagnosis of acute schistosomiasis mansoni, especially before the appearance of eggs in the faeces, are well known (Neves 1992, Rabello 1995, Lambertucci 1997). In the collected data, this fact was expressed by three occurrences: firstly, the number of medical facilities searched per patient. The number of 12 patients $(70.5 \%)$ visited two or more facilities before establishing the right diagnosis. One of the patients stated: "I saw five doctors. All treated me for common flu but I just became worse. The allergist whom I consulted because of the spots on my skin and my swollen face finally thought of schistosomiasis". Secondly, the different laboratory examinations performed per patient indicate that due to the lack of a reliable diagnostic hypothesis, an unspecified search for positive results started. Examinations such as blood culture, antistreptolysin $\mathrm{O}$ antibodies, anti hepatitis A and B antibodies were the most commonly requested. One of the infected individuals said: "I spent a little fortune with the examinations requested by the doctors. With more knowledge of this disease I could have saved a lot of money". Thirdly, the initial treatment given also confirms these difficulties. Many patients were medicated for common flu, bronchitis or unspecified enteritis. One patient was treated for sinusitis and various patients received antibiotics, which are useless in this case.

In this context the importance of the common epidemiological background is to emphasize, because it gives the hint to match the symptoms to the early stage of this specific disease and to establish a diagnosis. The reason for this delay in finding the right diagnosis may be caused by a lack of information available to diagnose acute schistosomiasis among health professionals at the level of the patient's first contact with the health system or simply the fact, that nobody thought about acute schistosomiasis because treatment was searched for in a low endemic area. In other words, there is lack of education for health professionals. In trying to overcome this shortfall we provided literature about the symptomatology of acute schistosomiasis as well as case reports about this topic for some of the medical facilities involved in this study. But these punctual and spontaneous contributions have to be institutionalized to ensure provision of adequate educational material for health professionals of all levels. This issue gains even more importance considering nation-wide decentralization of health system, that often leaves the local health authorities overwhelmed and overstretched in completing this task.

Having in mind the statements of the patients about the initial treatment for common flu, bronchitis, unspecified enteritis and others and the fact that acute schistosomiasis is a self-limited disease (Rabello 1995), the probability of many undetected cases must be considered. This consideration is confirmed by our data that patients, especially those with light symptoms, received specific treatment only after being informed about the disease by 
other members of the group or members of the research team. In this context it is worth mentioning, that three months later a control stool examination was carried out in 20 individuals of the original group of the 24 infected. All 18 people from the study and two other individuals participated. One of the two persons tested positive, although he did not show any symptom at the time of this examination. This occurrence corroborates the possibility of undetected non-symptomatic transmitters.

Another very important factor is the lack of knowledge among the infected individuals. How can somebody who does not know anything or only fragments about a disease be aware of its ways of transmission and consequently prevent an infection? The exploratory knowledge investigation of the group also showed that the current strategy in health education proved insufficient to create permanent knowledge of at least the basics of the disease. The majority of individuals heard about the disease in school more than five years ago. Furthermore the information acquired in school was not strengthened and consequently forgotten. Schall (1998) lined out new models of health education in childhood, as well as for adults, that can help to overcome these shortfalls. In a more recent publication about information and education in schistosomiasis control, Schall and Diniz (2001) emphasize that community participation is an important factor for strengthening knowledge of this disease within a population. As a model may also serve the so called "home land museums" in Europe or the "science centers" in the United States. These institutions are multi-purpose community centers, which serve as source of information for the local population, students and even for tourists. These centers represent a valuable tool in community based health education.

\section{REFERENCES}

Amorim MN, Rabello A, Contreras RL, Katz N 1997. Epidemiological characteristics of Schistosoma mansoni infection in rural and urban endemic areas of Minas Gerais, Brazil. Mem Inst Oswaldo Cruz 92: 577-580.

Barbosa CS 1998. Epidemiology and anthropology: an integrated approach dealing with bio-socio-cultural aspects as strategy for the control of endemic diseases. Mem Inst Oswaldo Cruz 93 (Suppl. 1): 59-62.

Barbosa CS, Domingues AL, Abath FG, Montenegro SML, Guida U, Carneiro J, Tabosa B, Lins de Moraes CN, Spinelli V 2001a. Epidemia da esquistossomose aguda na praia de Porto de Galinhas, Pernambuco, Brasil. Cad Saúde Públ 17: 725-728

Barbosa CS, Montenegro SML, Abath FG, Domingues AL 2001b. Specific situations related to acute schistosomiasis in Perambuco, Brazil. Mem Inst Oswaldo Cruz 96 (Suppl. 5): $169-172$.

Carmo EH, Barreto ML 1994. Esquistossomose mansônica no Estado da Bahia, Brasil: tendências históricas e medidas de controle. Cad Saúde Públ 10: 425-439.

Coura JR, Coura LC, Kalache A, Argendo CA 1970. Esquistossomose aguda autóctone de foco na cidade do Rio de Janeiro. Estudo de 22 casos. Rev Soc Bras Med Trop 6: 387-396.

Coura-Filho P 1997a. Distribuição da esquistossomose no espaço urbano. 1. O caso da região metropolitana de Belo Horizonte, Minas Gerais, Brasil. Cad Saúde Públ 13: $245-$ 255.

Coura-Filho P 1997b. Distribuição da esquistossomose no espaço urbano. 2. Aproximação teórica sobre a acumulação, concentração, centralização do capital e a produção de doenças. Cad Saúde Públ 13: 415-424.

Ferreira H, Oliveira CA, Bittencourt D, Katz N, Carneiro LFC, Grinbaum E, Veloso C, Dias RP, Alvarenga RJ, Dias CB. 1966. A fase aguda da esquistossomose mansoni. J Bras Med 11: 54-67.

Ferreira LF, Naveira JB, Silva JR 1960. Fase toxêmica da esquistossomose mansoni. Rev Inst Med Trop São Paulo 2: 112-120.

Grault CE, Silva CCCM, Costa MJFS, Lenzi MF, Cruz OJ, Almeida AS, Silva MQ, Bezerra RMP, Costa V 1998. Potential spread of schistosomiasis in the periphery of greater metropolitan region of Rio de Janeiro. Mem Inst Oswaldo Cruz 93 (Suppl. 1): 293-294.

Katz N 1998. Schistosomiasis control in Brazil. Mem Inst Oswaldo Cruz 93 (Suppl. 1): 33-35.

Katz N, Peixoto SV 2000. Análise crítica da estimativa do número de portadores de esquistossomose mansoni no Brasil. Rev Soc Bras Med Trop 33: 303-308.

Katz N, Chaves A, Pellegrino J 1972. A simple device for quantitative stool thick-smear technique in schistosomiasis mansoni. Rev Inst Med Trop São Paulo 14: 397-400.

Lambertucci JR, Rayes AAM, Barata $\mathrm{CH}$, Teixeira R, Gerspacher-Lara R 1997. Acute schistosomiasis: report on five singular cases. Mem Inst Oswaldo Cruz 92: 631-635.

Manson-Bahr PEC, Bell DR 1989. Manson's Tropical Diseases, 19th ed., Bailliére Tindall, London, p. 448-485.

Neves J 1992. Acute or toxemic form of mansoni's schistosomiasis (Forma aguda ou toxêmica da esquistossomose mansoni). Mem Inst Oswaldo Cruz 87 (Suppl. 4): 321-324.

Rabello A 1995. Acute human schistosomiasis mansoni. Mem Inst Oswaldo Cruz 90: 277-280.

Schall VT 1998. An interactive perspective of health education for the tropical disease control: the schistosomiasis case. Mem Inst Oswaldo Cruz 93 (Suppl.1): 51-58.

Schall VT, Diniz MCP 2001. Information and education in schistosomiasis contol: an analysis of the situation in the state of Minas Gerais, Brazil. Mem Inst Oswaldo Cruz 96 (Suppl. 5): 35-43.

Sturrock RF 2001. Schistosomiasis epidemiology and control: how did we get here and where should we go? Mem Inst Oswaldo Cruz 96 (Suppl. 5): 17-27.

Suassuna A, Coura JR 1969. Esquistossomose mansoni no Estado da Guanabara - Aspectos epidemiológicos relacionados às migracões internas. Rev Soc Bras Med Trop 2: 59-71.

Thiengo S 1995. Técnicas malacológicas. In FS Barbosa, Tópicos em Malacologia Médica, Fiocruz, Rio de Janeiro, p. 255260. 